\title{
Binding of p-mercaptobenzoic acid and adenine to gold-coated electroless etched silicon nanowires studied by surface-enhanced Raman scattering
}

\author{
Vlasta Mohaček-Grošev ${ }^{\mathrm{a}, *}$, Hrvoje Gebavi ${ }^{\mathrm{a}}$, Alois Bonifacio ${ }^{\mathrm{b}}$, Valter Sergo ${ }^{\mathrm{b}}$, \\ Marko Daković ${ }^{c}$, Danica Bajuk-Bogdanović ${ }^{c}$ \\ a Centre of Excellence for Advanced Materials and Sensing Devices, Ruđer Bošković Institute, Bijenička cesta 54, 10002 Zagreb, Croatia \\ b University of Trieste, Via Valerio 6/A, Trieste, Italy \\ c Faculty of Physical Chemistry, University of Belgrade, Studentski trg 15-16, 11000 Belgrade, Serbia
}

\section{A R T I C L E I N F O}

\section{Article history:}

Received 21 July 2017

Received in revised form 30 March 2018

Accepted 9 April 2018

Available online 10 April 2018

\section{Keywords:}

Silicon nanowires

Normal mode analysis

Substrate binding

Biosensors

SERS

Mercaptobenzoic acid

Hot spots mapping

\begin{abstract}
A B S T R A C T
Modern diagnostic tools ever aim to reduce the amount of analyte and the time needed for obtaining the result. Surface-enhanced Raman spectroscopy is a method that could satisfy both of these requirements, provided that for each analyte an adequate substrate is found. Here we demonstrate the ability of gold-sputtered silicon nanowires (SiNW) to bind p-mercaptobenzoic acid in $10^{-3}, 10^{-4}$ and $10^{-5} \mathrm{M}$ and adenine in 30 and $100 \mu \mathrm{M}$ concentrations. Based on the normal mode analysis, presented here for the first time, the binding of p-mercaptobenzoic acid is deduced. The intensity enhancement of the $1106 \mathrm{~cm}^{-1}$ band is explained by involvement of the $\mathrm{C}-\mathrm{S}$ stretching deformation, and the appearance of the broad $300 \mathrm{~cm}^{-1}$ band attributed to $\mathrm{S}-$ Au stretching mode. Adenine SERS spectra demonstrate the existence of the $7 \mathrm{H}$ tautomer since the strongest band observed is at $736 \mathrm{~cm}^{-1}$. The adenine binding is likely to occur in several ways, because the number of observed bands in the $1200-1600 \mathrm{~cm}^{-1}$ interval exceeds the number of observed bands in the normal Raman spectrum of the free molecule.
\end{abstract}

(c) 2018 Elsevier B.V. All rights reserved.

\section{Introduction}

Since the discovery of surface-enhanced Raman scattering (SERS) by Fleischmann [1], Van Duyne [2], and Creighton [3], many research efforts have been dedicated to understand this effect [4-8]. Broadly speaking, SERS effect takes place if the metal substrate possesses an electronic state whose energy lies between the energy of the laser excitation and the energy of Raman scattered light, thus facilitating a "localized surface plasmon resonance" [9]. Originally the effect was studied first in colloidal silver [10] and gold nanoparticles aggregates [11], reaching a sensitivity down to single molecule detection [12,13].

The possibilities of SERS effect on solid substrates have soon surpassed those of free flowing aggregates, because of better reproducibility [14-16]. The importance of nanoscale dimensions of metal particles has been investigated and repeatedly proven essential for the SERS to take place $[17,18]$. Besides electromagnetic contribution to enhancement, a chemical one is often mentioned, but it is several orders of

\footnotetext{
* Corresponding author.

E-mail address: Vlasta.Mohacek.Grosev@irb.hr. (V. Mohaček-Grošev).
}

magnitude smaller [4]. Few molecules with strong resonant Raman spectrum have become very popular for testing substrates - one is rhodamine 6G, another crystal violet. Both of them incorporate several aromatic rings having delocalized electron orbitals. The UV VIS spectrum of crystal violet, for example, changes dramatically depending on the $\mathrm{pH}$ of the solution. When the $\mathrm{pH}$ is 1 , the absorbance has its maximum in the blue spectral region, while it shifts to red if the $\mathrm{pH}$ changes to 4 [19]. Still, when testing new substrates it is advisable to check their properties with non-resonant molecules [9].

Among numerous applications of SERS, the possibility of detecting an extremely small quantity of an analyte in blood, urine or saliva within minutes has attracted a lot of attention, and has been a part of study effort within the COST action [20]. Two main strategies offer themselves: the first is to devise a label-free method of detection, thus concentrating on a substrate itself [21], and the second one is to devise a chemical marker which binds to the analyte and to the substrate and through which one ascertains the existence of analyte [22,23].

Here we present the results of a joint effort to produce a reliable substrate with good reproducibility based on electroless chemical etching method. This method dates from 2002 [24]., is cost effective and produces silicon nanowires $50-100 \mathrm{~nm}$ in diameter and several tens of $\mu \mathrm{m}$ in length [25-37]. In contrast to electrochemical etching that is 
also often used, here there is no external voltage applied in electrochemical cell, but hydrogen fluoride or ammonia fluoride providing excess electrons to ionize silver atoms [25-27]. Gold particles are added on the top of the substrate, thus creating optimal binding surface for Raman spectroscopy with near infrared $(785 \mathrm{~nm}$ ) laser. Welding of a silicon nanowire with a gold droplet produces an atomic force microscopy tip that serves as a probe for tip-enhanced Raman spectroscopy (TERS) [28-30]. We present SERS spectra of p-mercaptobenzoic acid (4MBA), and discuss possible types of molecular binding. By performing normal coordinate calculation, we elucidate the nature of observed spectral changes which appear on binding of 4MBA to the substrate.

\section{Experimental}

Silicon wafers - (100) orientation - single crystalline p-type, were cleaned with standard RCA (Radio Corporation of America) cleanup processes. The mixture of hydrofluoric acid ( $5 \mathrm{M}$ ) and $\mathrm{AgNO}_{3}$ solution under UV lamp was utilized for synthesizing silicon nanowires by electroless wet chemical etching method during period of $90 \mathrm{~min}$. The experiment was carried at ambient temperature of $26^{\circ} \mathrm{C}$. After etching, the samples were covered with grey silver layer which was removed with $\mathrm{NH}_{4} \mathrm{OH}: \mathrm{H}_{2} \mathrm{O}_{2}: \mathrm{H}_{2} \mathrm{O}$ solution using the $1: 1: 5$ volume-to-volume ratio. The samples were rinsed with $\mathrm{MQ}$ water and dried. Next step included gold sputtering of silicon nanowires during various time intervals. For the etching of the first group of samples the $30 \mathrm{mM}$ concentration of $\mathrm{AgNO}_{3}$ was used, the sputtering was performed during $1,10,15$ or $20 \mathrm{~min}$ and all were annealed at $650^{\circ} \mathrm{C}$ in the oven under argon flow for one hour. The second group of substrates was etched using two concentrations of $\mathrm{AgNO}_{3}: 10$ and $30 \mathrm{mM}$, they were sputtered during 7, 10, 15 or $20 \mathrm{~min}$. Samples from the second group were further divided into one half that was annealed at $650^{\circ} \mathrm{C}$, while the other half which was not annealed.

\subsection{Gold coating}

For sputtering a Polaron E5000 sputter coater was used. The vacuum obtained prior to Au sputtering was $10^{-5}$ mbar. During the sputtering argon plasma was utilized and the pressure inside the

Table 1

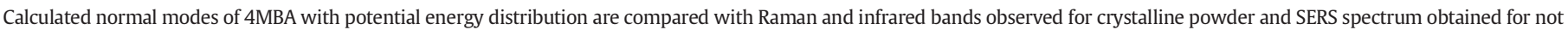

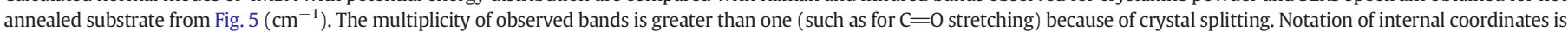
explained in Supplementary Material.

\begin{tabular}{|c|c|c|c|c|}
\hline \multirow[t]{2}{*}{ Mode } & & \multicolumn{2}{|l|}{ Observed (crystal) } & \multirow[t]{2}{*}{ Observed (SERS) } \\
\hline & & Raman & Infrared & \\
\hline \multicolumn{5}{|l|}{$\mathrm{A}^{\prime}$} \\
\hline 3763 & 1001 & Not acq. & Not acq. & Not acq. \\
\hline 3228 & $100 \mathrm{r}$ & Not acq. & Not acq. & Not acq. \\
\hline 3219 & $100 \mathrm{r}$ & Not acq. & Not acq. & Not acq. \\
\hline 3194 & $100 \mathrm{r}$ & Not acq. & Not acq. & Not acq. \\
\hline 3191 & $100 \mathrm{r}$ & Not acq. & Not acq. & Not acq. \\
\hline 2694 & $100 \mathrm{~s}$ & Not acq. & Not acq. & Not acq. \\
\hline 1783 & $81 \mathrm{D}$ & $1676,1655,1643,1638$ & $1694,1679,1652$ & 1689 \\
\hline 1644 & $67 \mathrm{R}+21 \Phi+10 \Omega$ & $1632,1624,1615$ & 1593 & \\
\hline 1604 & $74 R+10 \Phi$ & 1599 & 1564 & 1589 \\
\hline 1529 & $59 \Phi+34 R$ & 1456 & 1493 & \\
\hline 1445 & $51 \mathrm{R}+40 \Phi$ & 1405 & $1444,1424,1402$ & 1482 \\
\hline 1376 & $26 \varepsilon+21 d+18 C C+18 \kappa$ & & & 1414 \\
\hline 1346 & $76 \mathrm{R}+13 \Phi$ & 1322 & 1323,1308 & \\
\hline 1333 & $73 \Phi+23 R$ & 1296 & 1296 & \\
\hline 1223 & $47 \Phi+22 \mathrm{R}+21 \varepsilon$ & 1286 & $1281,1263,1232$ & 1281 \\
\hline 1194 & $36 \Phi+31 \varepsilon+13 R$ & 1185 & 1182 & 1178 \\
\hline 1144 & $60 \Phi+33 R$ & 1138 & 1130 & \\
\hline 1120 & $28 R+26 d+16 \Phi$ & & 1115 & \\
\hline 1106 & $56 R+19 d+13 S$ & 1100 & $1096,1086,1051$ & 1077 \\
\hline 1030 & $61 \Omega+27 \mathrm{R}$ & 1075 & 1015 & 1014 \\
\hline 944 & $91 \delta_{\mathrm{s}}$ & 914 & 956,925 & \\
\hline 793 & $29 \mathrm{R}+29 \Omega+15 \mathrm{CC}$ & 804 & 831,805 & 802 \\
\hline 672 & $36 \kappa+21 \Omega+14 \mathrm{~S}$ & 700 & 710 & 692 \\
\hline 644 & $83 \Omega+10 \mathrm{R}$ & 635 & 632 & 631 \\
\hline 520 & $29 \eta+23 S+13 C C$ & & 546 & \\
\hline 496 & $27 \kappa+23 \eta+14 \delta_{C}$ & & 518 & \\
\hline 308 & $37 \Omega+17 \mathrm{~S}+16 \mathrm{CC}+12 \kappa$ & 344 & & 335 \\
\hline 298 & $54 \delta_{S}+15 \kappa+13 \delta_{C}$ & 276 & & 298 \\
\hline 168 & $52 \mathrm{CC}+22 \mathrm{~S}+18 \kappa$ & 186 & & \\
\hline \multirow[t]{2}{*}{ Mode } & PED (\%) & \multicolumn{2}{|l|}{ Observed (crystal) } & Observed (SERS) \\
\hline & & Raman & Infrared & \\
\hline \multicolumn{5}{|l|}{$\mathrm{A}^{\prime \prime}$} \\
\hline 991 & $100 \mu$ & & & \\
\hline 978 & $100 \mu$ & & 974 & \\
\hline 851 & $71 \mu+30 \mu \mathrm{SC}$ & 818 & 848 & 848 \\
\hline 841 & $98 \mu$ & 812 & 848 & \\
\hline 765 & $70 \mu \mathrm{SC}+29 \mu$ & & 757 & 763 \\
\hline 680 & $93 \delta$ & & 684 & 716 \\
\hline 595 & $85 \tau \mathrm{OH}+11 \delta$ & & 576 & \\
\hline 472 & $47 \delta+46 \mu S C$ & & 470 & 407 \\
\hline \multicolumn{5}{|l|}{414} \\
\hline 259 & $80 \mu S C+19 \delta$ & 249 & & \\
\hline 156 & 100 TSC & 223,205 & & \\
\hline 88 & $56 \delta+44 \mu \mathrm{CC}$ & 84 & & \\
\hline 71 & 97 тосCС & 79 & & \\
\hline
\end{tabular}


chamber was $4 \cdot 10^{-4}$ mbar. The Au layer thickness is estimated to increase linearly with time, and is assumed to be between 100 and $150 \mathrm{~nm}$ for $40 \mathrm{~min}$ of sputtering.

\subsection{Raman measurements}

Raman experiments were conducted on four instruments: T64000 Horiba Jobin-Yvon with $670 \mathrm{~nm}$ laser for powder sample of 4MBA, Thermo Scientific DXR Raman microscope with 785 laser illumination which was used for SERS droplet experiments, BWTek i-Raman Plus with $785 \mathrm{~nm}$ laser for SERS immersion experiments, and Renishaw InVia spectrometer with $785 \mathrm{~nm}$ laser source for Raman mapping. Each of these four setups is described in detail:

\subsection{Raman and infrared spectra of polycrystalline $4 M B A$}

Polycrystalline powder of 4-MBA was put on a glass slide under microscope of HORIBA Jobin Yvon T64ooo Raman spectrometer operating
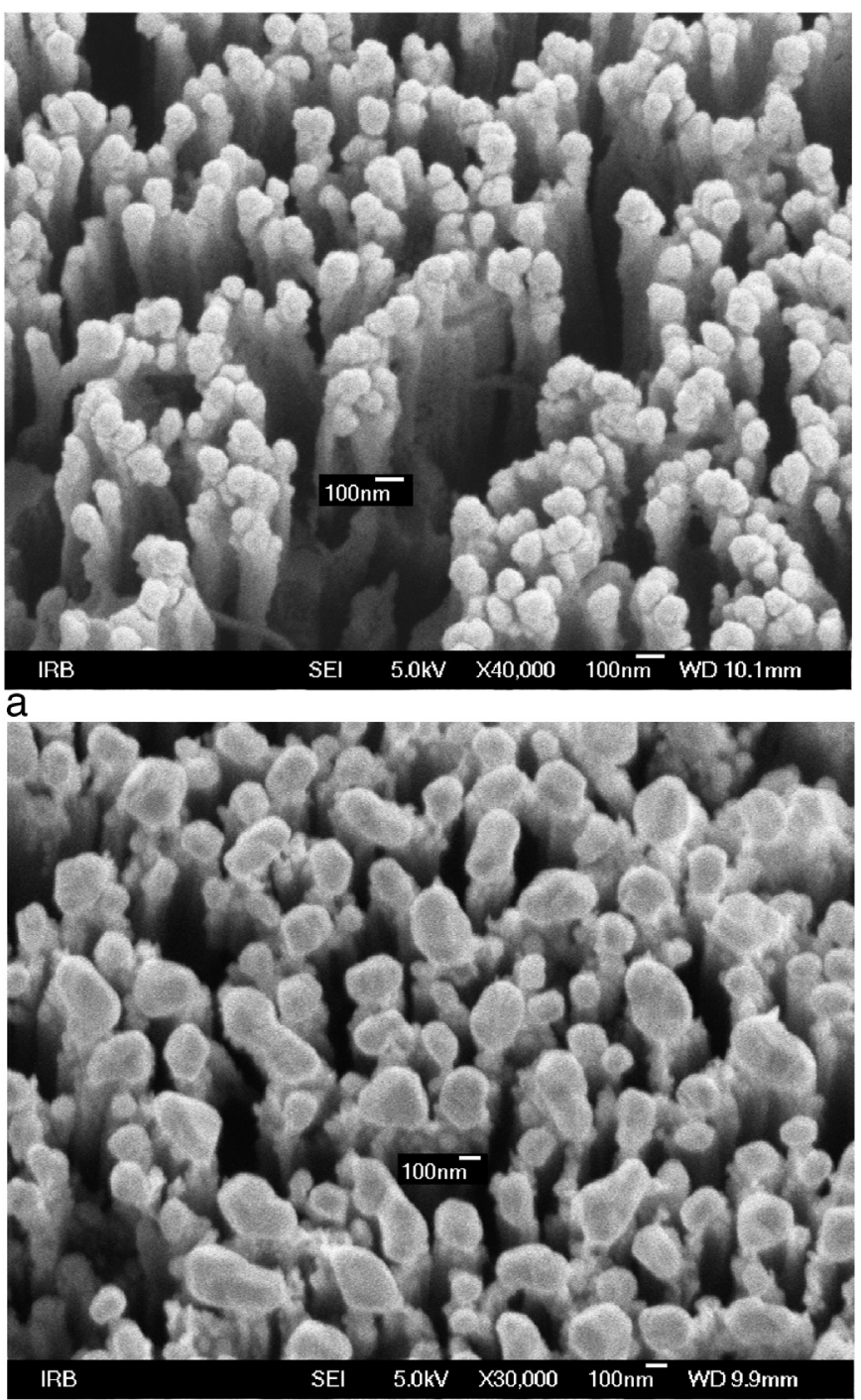

b

Fig. 1. Scanning electron microscopic images of silicon nanowires obtained by electroless chemical etching ( $30 \mathrm{mM} \mathrm{AgNO}_{3} / 5 \mathrm{M} \mathrm{HF}$ solution) with gold sputtered for $20 \mathrm{~min}$. a) not annealed substrate, b) substrate annealed at $650^{\circ} \mathrm{C}$ for $1 \mathrm{~h}$ in argon atmosphere. The bar corresponds to $100 \mathrm{~nm}$. The tilt angle was $15^{\circ}$. (For interpretation of the references to colour in this figure legend, the reader is referred to the web version of this article.) in triple subtractive mode, using $670 \mathrm{~nm}$ red excitation laser line with power of $3 \mathrm{~mW}$ on the sample. Spectral resolution was $0.6 \mathrm{~cm}^{-1}$ and the spot size $1 \mu \mathrm{m}$. Infrared spectra of 4MBA powder pressed in $\mathrm{KBr}$ pellet were obtained in transmission by Perkin Elmer Spectrum GX mode, with 20 repetitions and $4 \mathrm{~cm}^{-1}$ resolution. The observed bands are reported in Table 1.

\subsection{Raman SERS spectra of the first group of substrates - droplet method}

The SERS spectra using the annealed substrates etched for $1,10,15$ or 20 min with $5 \mathrm{M} \mathrm{HF} / 30 \mathrm{mM} \mathrm{AgNO}_{3}$ were obtained by leaving a $1 \mu \mathrm{l}$ droplet of $0.01 \mathrm{M} 4 \mathrm{MBA}$ on a surface and recording the Raman signal immediately using Thermo Scientific DXR Raman microscope operating with $785 \mathrm{~nm}$ laser excitation line. Spectral resolution of this instrument was $4 \mathrm{~cm}^{-1}$. The acquisition time was $10 \mathrm{~s}$, the pinhole was $50 \mu \mathrm{m}$, and four accumulations were performed. In order to test the limit of detection SERS spectra of droplets from $10^{-3} \mathrm{M}, 10^{-4} \mathrm{M}$ and $10^{-5} \mathrm{M}$ solutions of 4MBA were recorded.

\subsection{Raman SERS spectra of the second group of substrates - immersion method}

Substrates from the second group were immersed either into a $1 \mathrm{mM} 4 \mathrm{MBA}$ water solution, or into $30 \mu \mathrm{M}$ or $100 \mu \mathrm{M}$ adenine water solution for $30 \mathrm{~min}$, taken out, rinsed and dried. SERS spectra using the substrates of the second group were recorded by portable BWTek iRaman Plus spectrometer using $20 \times$ objective and $785 \mathrm{~nm}$ excitation suitable for gold sputtered surfaces, with spectral resolution of $4 \mathrm{~cm}^{-1}$. The spot diameter was $80 \mu \mathrm{m}$, the acquisition time $5 \mathrm{~s}$ and a single accumulation of the spectrum undertaken. Besides $1 \mathrm{mM} 4 \mathrm{MBA}$ concentration, a sensitivity test included $10^{-4} \mathrm{M}, 10^{-5} \mathrm{M}, 10^{-6} \mathrm{M}$ and $10^{-7} \mathrm{M}$ 4MBA water and ethanol solutions.

\subsection{Raman mapping}

The spectral mapping of the $1520-1640 \mathrm{~cm}^{-1}$ Raman interval of 4MBA was performed with Renishaw INVIA spectrometer, operating with $785 \mathrm{~nm}$ laser source, on two selected substrates, both etched with $5 \mathrm{M} \mathrm{HF}$ and $30 \mathrm{mM} \mathrm{AgNO}_{3}$ solution, sputtered for 20 min with gold, one annealed and the other not annealed. The intensity maps were analyzed using the HyperSpec package [39] for R [40].

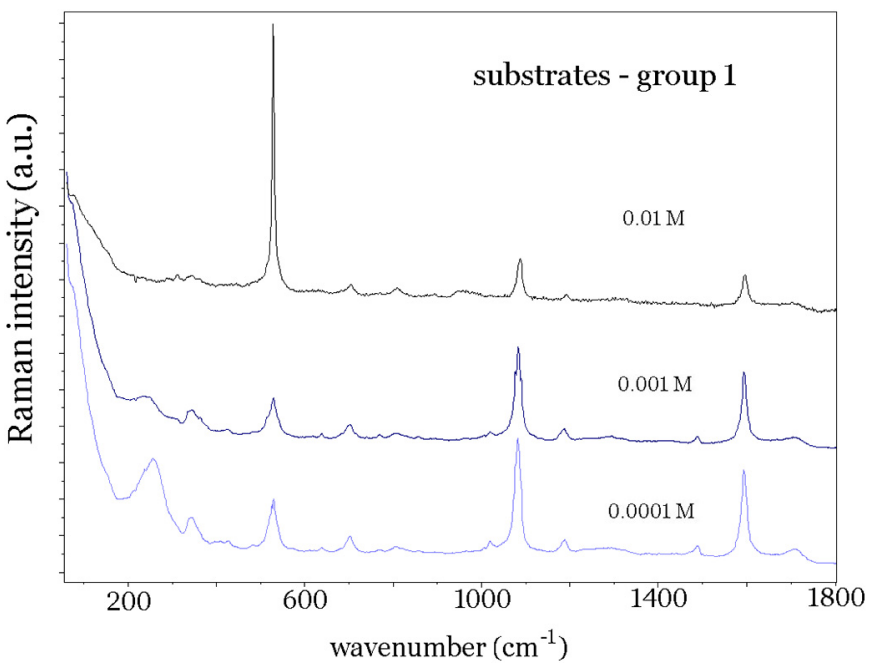

Fig. 2. Comparison of SERS spectra of wet droplets of 4MBA ethanol solution on AuNP@ SiNW substrates. Laser excitation: $785 \mathrm{~nm}$, Thermo Scientific DXR Raman spectrometer. 

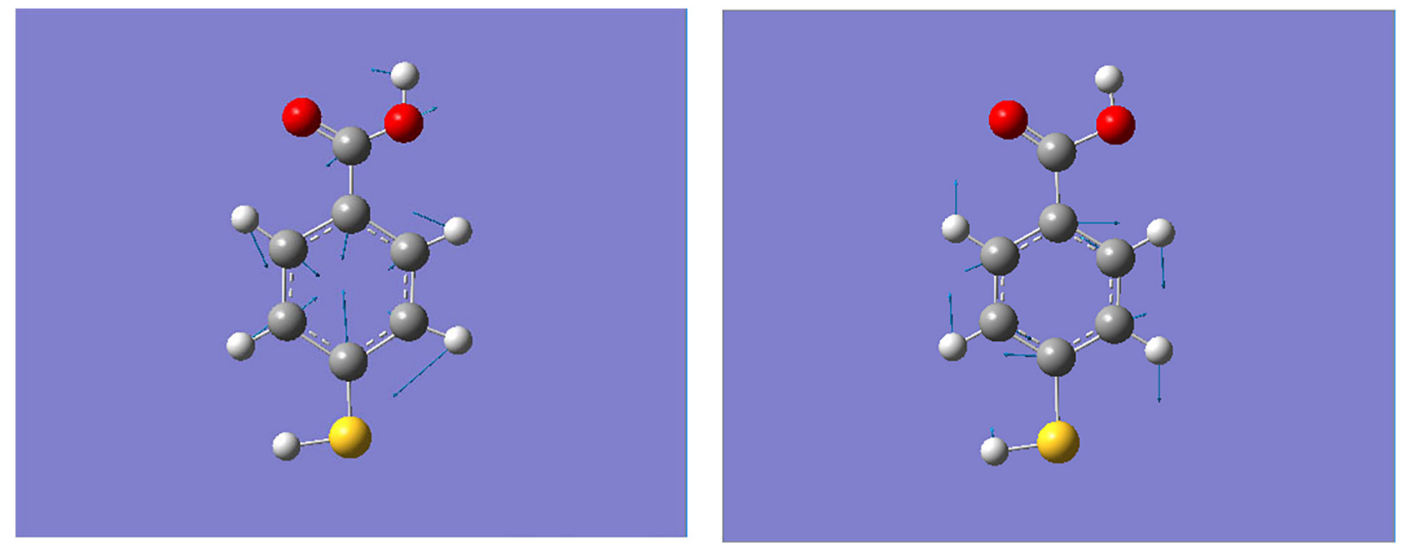

Fig. 3. Arrows indicate movements of atoms in the two strongest normal modes of free 4MBA: calculated at 1106 (left) and $1604 \mathrm{~cm}^{-1}$ (right).

\subsection{Scanning electron microscopy}

Scanning electron microscopy of silicon nanowires substrates was performed using JEOL field emission SEM, model JEOL JSM-7000F, with acceleration voltage of $5 \mathrm{kV}$.

\subsection{Computational details}

Optimization of the geometry of the 4-mercaptobenzoic acid was performed using Gaussian03 program [41], utilizing the implemented density functional theory through Becke exchange and Lee, Yang and Parr correlation functionals with $6-311 G(d, p)$ basis set. The subsequent

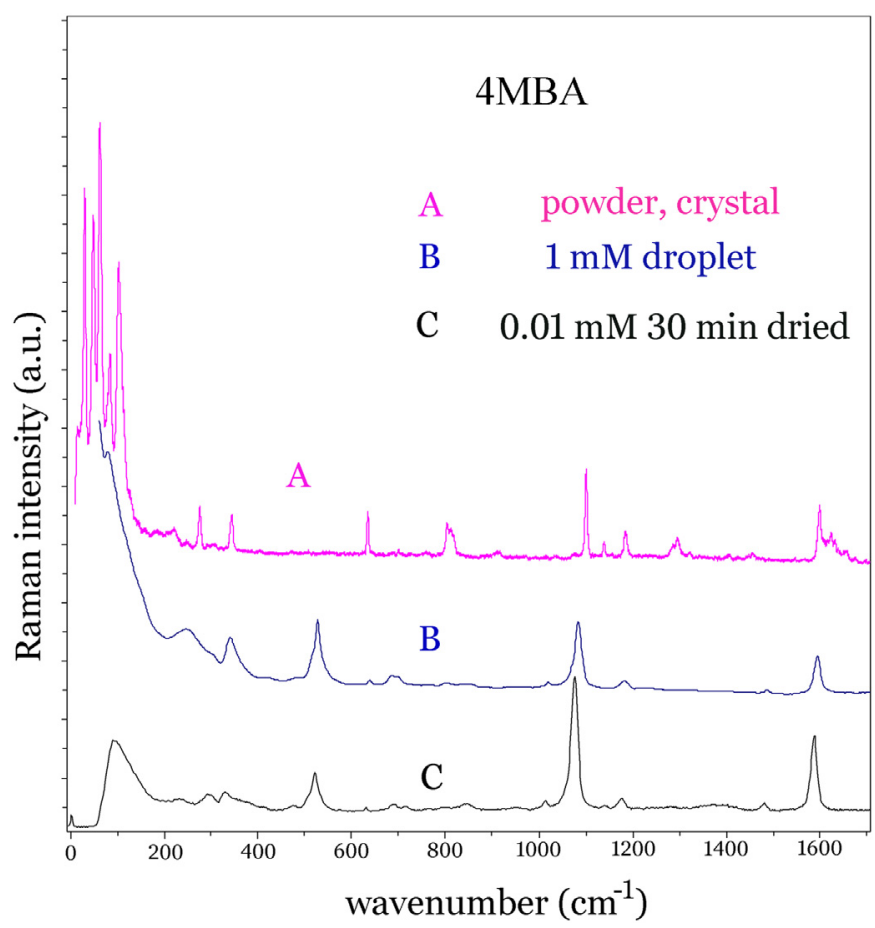

Fig. 4. Comparison of Raman spectrum of polycrystalline 4MBA (A) obtained with $670 \mathrm{~nm}$ laser, with the SERS spectrum of $1 \mathrm{mM} 4 \mathrm{MBA}$ droplet (B), and the SERS spectrum obtained by immersion of the substrate in the $0.01 \mathrm{mM}$ ethanol solution of $4 \mathrm{MBA}$ for $30 \mathrm{~min}$, rinsed and dried (C). (B) and (C) were obtained with $785 \mathrm{~nm}$ excitation. normal modes calculation proved that the geometry was indeed a stable state and no imaginary frequencies occurred. Introducing internal coordinates suitable for a planar molecule such as 4MBA, we used MOLVIB program by Krisztof Kuczera [42] and obtained a potential energy distribution among normal modes. Details of this calculation are part of the Supplementary Material.
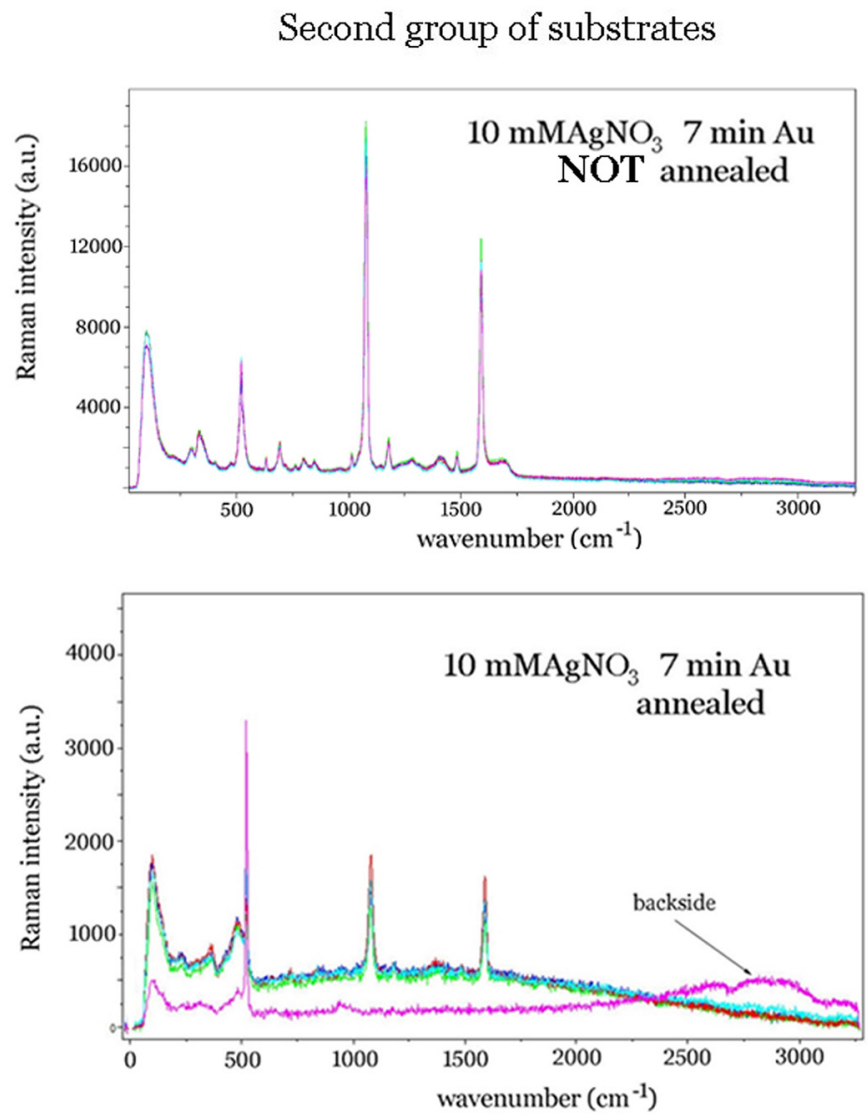

Fig. 5. SERS spectra of $1 \mathrm{mM}$ solution of $4 \mathrm{MBA}$ (substrates were submerged for $30 \mathrm{~min}$ in $0.001 \mathrm{M}$ 4MBA solution in EtOH, rinsed and dried) with $785 \mathrm{~nm}$ excitation using $20 \times$ objective, $5 \mathrm{~s}$ accumulation time and 1 repetition, with BWTek i-plus spectrometer. Spectra shown above were taken on different points on a single substrate which was not annealed, spectra shown below on an annealed substrate. Spectrum of the backside of the same substrate is also shown. 

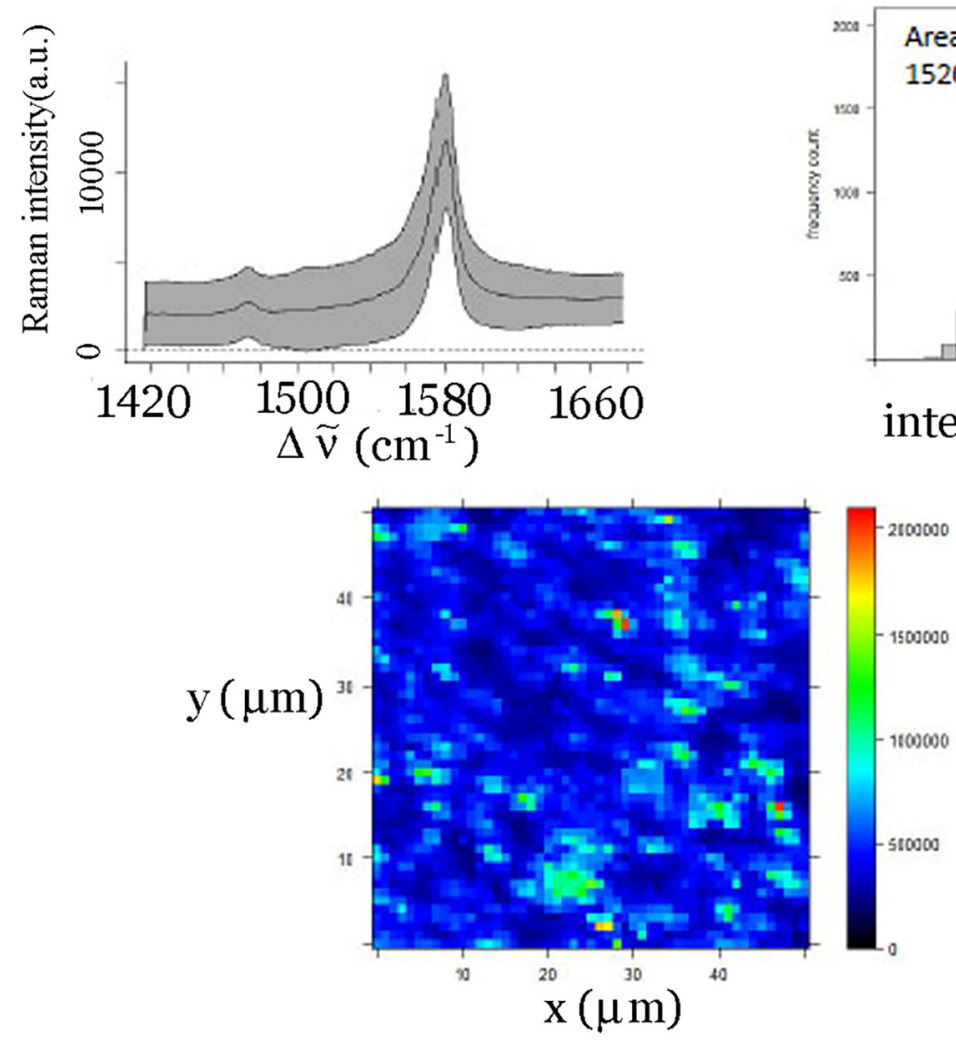

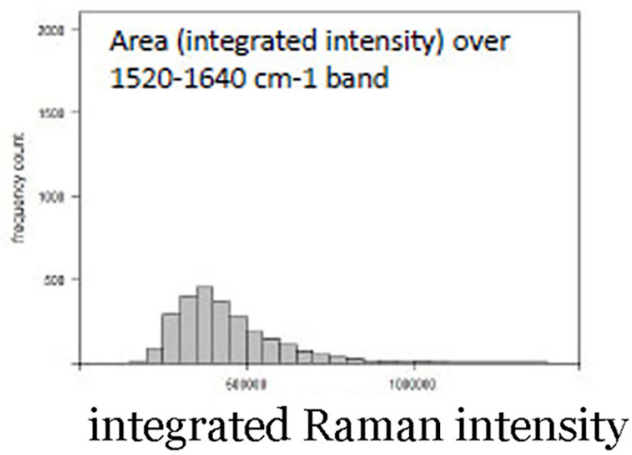

Map of area

(integrated intensity) over $1520-1640 \mathrm{~cm}-1$ band

(linear baseline has been substracted before integration)
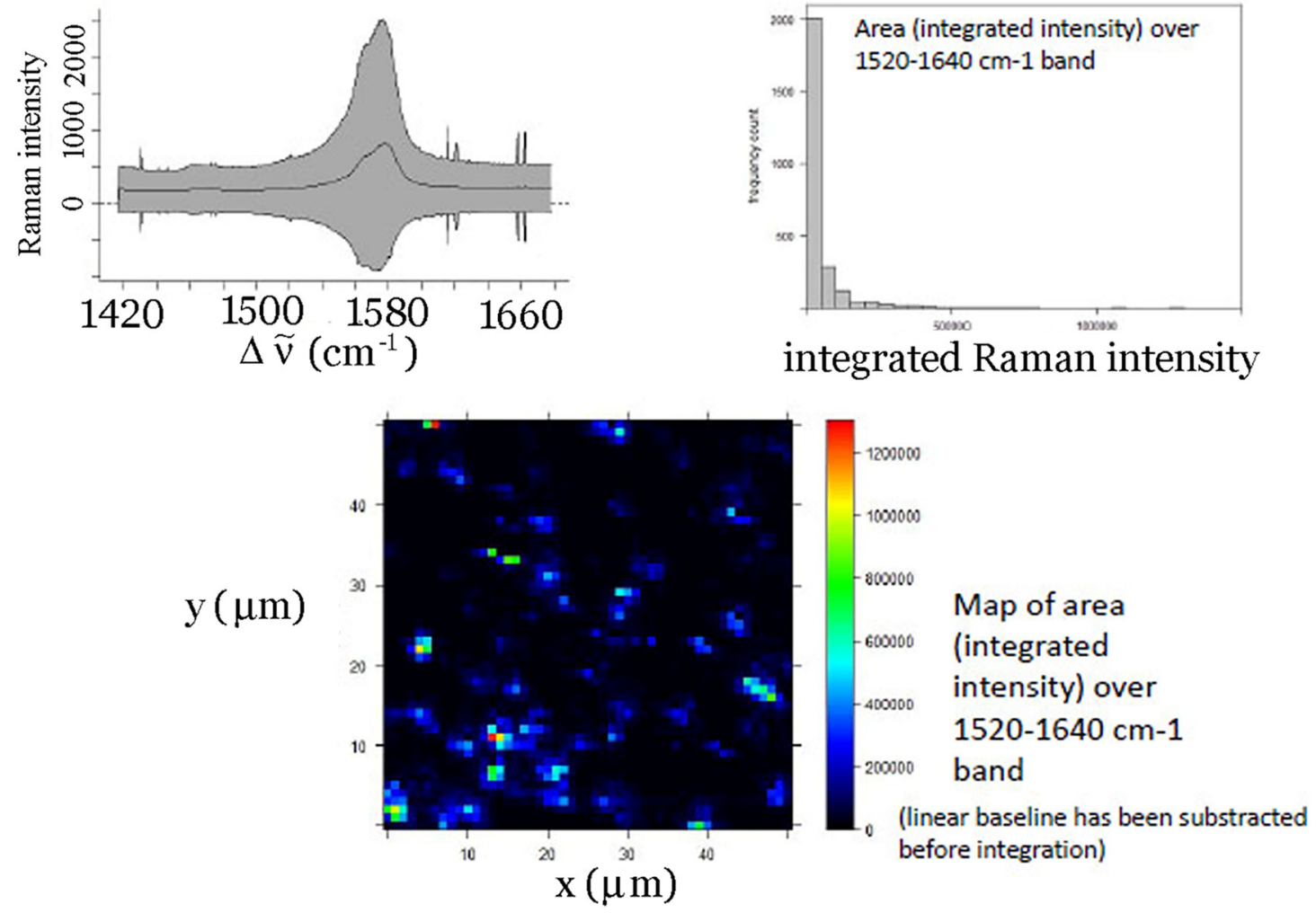

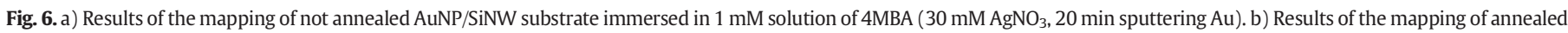
AuNP/SiNW substrate immersed in $1 \mathrm{mM}$ solution of $4 \mathrm{MBA}$ and rinsed ( $30 \mathrm{mM} \mathrm{AgNO}_{3}, 20$ min sputtering $\mathrm{Au}$ ). 


\section{Results and Discussion}

Scanning electron microscopic images of two selected substrates from the second group are displayed in Fig. 1. The diameters of silicon nanowires ( $\mathrm{SiNW}$ ) were 80 to $100 \mathrm{~nm}$, and their length from 1 to 1.1 $\mu \mathrm{m}$. The wires ran parallel to each other, occasionally producing entanglements, while their free ends were accessible to gold particles sputtered onto them. The voids between SiNWs grow larger when etching time exceeds $1 \mathrm{~h}$. The appearance of voids described by Bontempi et al. [31] was attributed to mechanical damage because SiNWs became brittle. The procedures of electroless chemical etching and metalassisted chemical etching refer to mainly the same procedure, sometimes without hydrogen peroxide $\mathrm{H}_{2} \mathrm{O}_{2}$ and sometimes exchanging $\mathrm{HF}$ with $\mathrm{NH}_{4} \mathrm{~F}$ [24-38]. Occasionally nanowires get entangled or joined at the top. The effect this has on SERS spectrum was discussed by Kara et al. [36] in their SERS spectrum of melamine. The strongest Raman band obtained with substrate with non-leaning SiNWs corresponded to the strongest band in the reference Raman spectrum of pure melamine $\left(676 \mathrm{~cm}^{-1}\right)$, while there were two strong bands obtained with substrate with leaning SiNWs, one shifted to $712 \mathrm{~cm}^{-1}$ and one notmuch-shifted from the reference $\left(680 \mathrm{~cm}^{-1}\right)$.

When chloroauric acid, $\mathrm{HAuCl}_{4} \cdot 3 \mathrm{H}_{2} \mathrm{O}$, is used for chemical deposition of gold on silicon nanowires, gold particles enter the vertical space between the wires, getting bigger towards the top [32-34]. Our hybrid sensors were produced by sputtering gold onto SiNWs, thus gold nanoparticles (AuNP) formed predominantly at SiNW tips. Their dimensions were in the range 120 to $230 \mathrm{~nm}$, while annealing caused coalescence of several AuNPs into a bigger one (Fig. 1.)

The suitability of our hybrid substrates for SERS is demonstrated in Fig.2, where droplets of different concentrations of 4MBA were deposited on a AuNP@SiNWs, which were not annealed. Spectra of droplets were recorded while the samples were still wet, focusing the image on the substrate/droplet interface. As the concentration of $4 \mathrm{MBA}$ is lowered, the band at $300 \mathrm{~cm}^{-1}$ that corresponds to the calculated value of $298 \mathrm{~cm}^{-1}$ for $\mathrm{C}-\mathrm{C}-\mathrm{S}$ in plane deformation is gaining the intensity.

The band at $528 \mathrm{~cm}^{-1}$ corresponds to the $A_{g}$ mode of the silicon, but is shifted from the value observed for crystal $\left(520.7 \mathrm{~cm}^{-1}\right)$. Also, shoulders appear on this band, probably coming from the 518 and $548 \mathrm{~cm}^{-1}$ modes observed in the infrared spectrum and too weak to be observed in normal Raman spectrum (Table 1, Supplementary Fig. S1). The two strongest 4MBA bands are observed at 1077 and $1589 \mathrm{~cm}^{-1}$, and the normal modes assigned to them depicted in Fig. 3.

The droplet technique is compared with immersion and drying technique in Fig. 4. The substrate is immersed in solution for $30 \mathrm{~min}$, then taken out, rinsed and left to dry. The crystal structure of 4MBA is unknown, therefore we could not calculate the positions of phonon bands for powder sample (spectrum A, Fig. 4.). The observed bands at
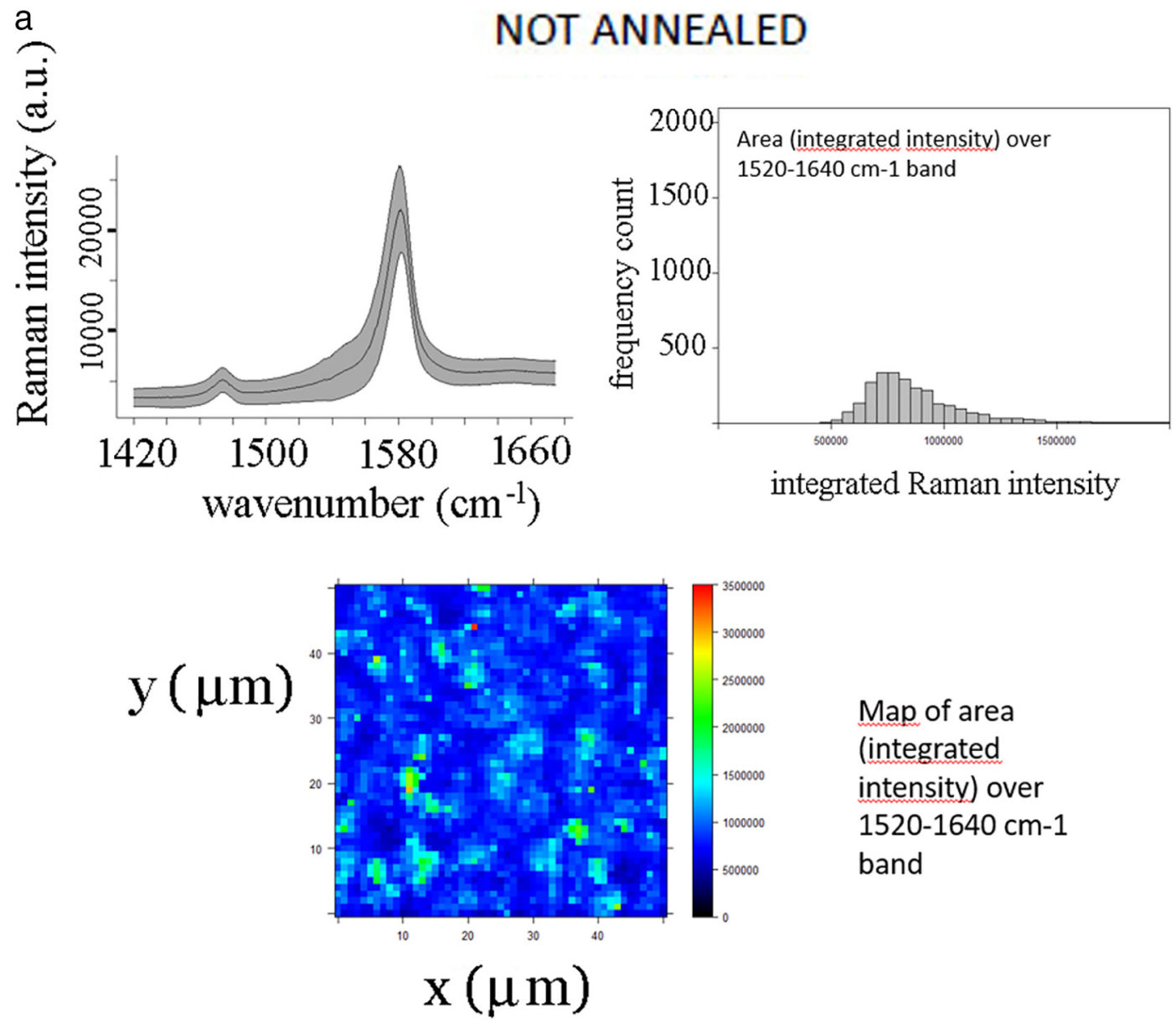

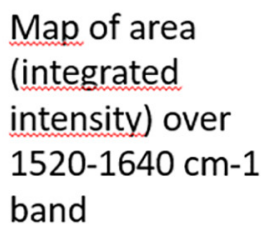

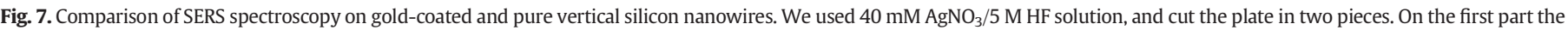

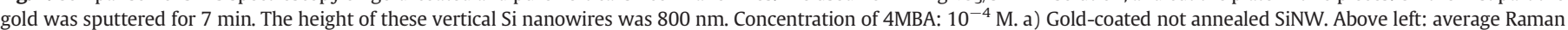

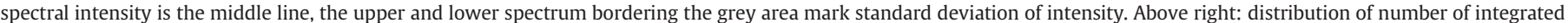

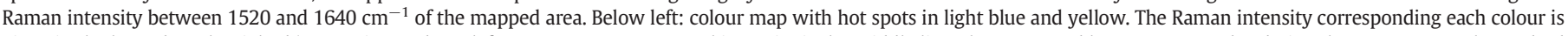

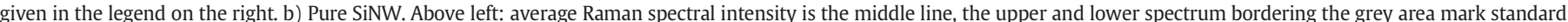

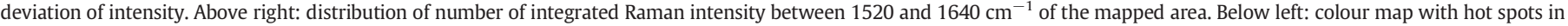

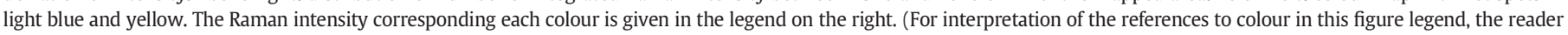
is referred to the web version of this article.) 
b

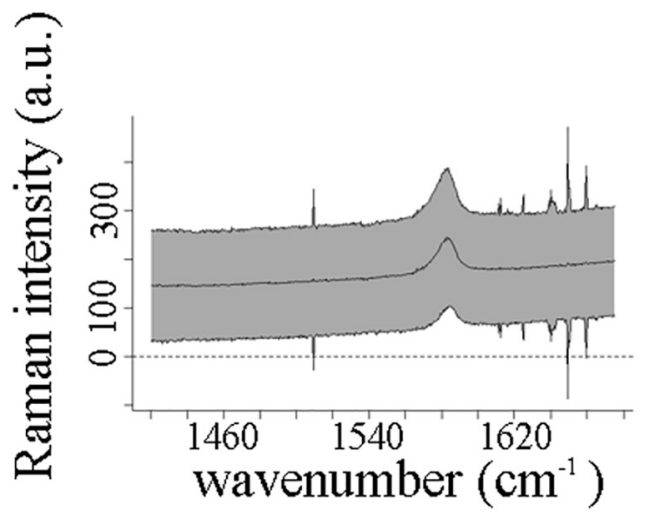

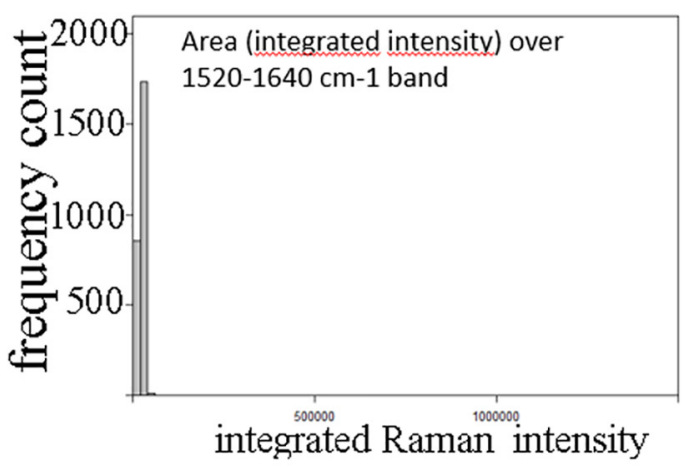

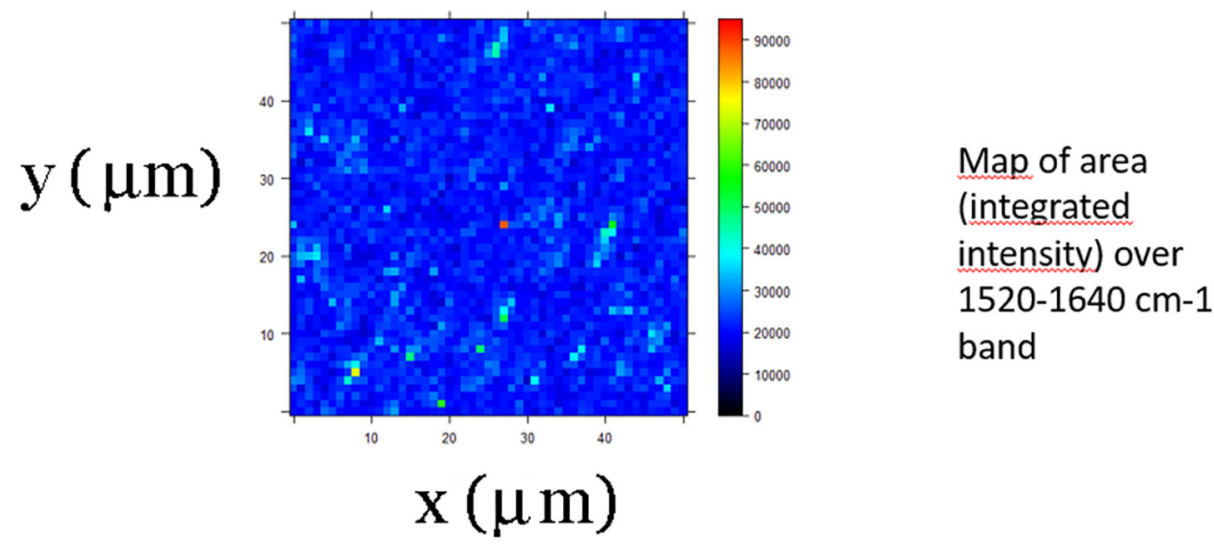

Fig. 7 (continued).

276 and $344 \mathrm{~cm}^{-1}$ are most probably internal molecular modes, since there exist three modes predicted for free 4MBA at 259, 298 and $308 \mathrm{~cm}^{-1}$ (see Table 1 where all calculated modes for free 4MBA are compared with the observed bands positions). The mode calculated at $259 \mathrm{~cm}^{-1}$ is out-of-plane deformation, while $298 \mathrm{~cm}^{-1}$ mode is $\mathrm{C}-\mathrm{C}$ $-\mathrm{S}$ bending deformation coupled with $\mathrm{C}-\mathrm{C}-\mathrm{O}$ bending deformation of the carboxylic group. The $308 \mathrm{~cm}^{-1}$ mode is also an in-plane mode containing $\nu(\mathrm{C}-\mathrm{S})$ and $\nu(\mathrm{C}-\mathrm{COOH})$ stretching motions. In SERS spectra from Fig. 5, bands at 298 and $335 \mathrm{~cm}^{-1}$ observed for not annealed substrates gain in the intensity. The shift of $27 \mathrm{~cm}^{-1}$ between the expected value of $308 \mathrm{~cm}^{-1}$ for free molecule and the observed band at $335 \mathrm{~cm}^{-1}$ in SERS spectrum points to the fact that binding to the goldcoated silicon nanowire substrate has taken place. Comparing not annealed and annealed substrates, we find that there are no bands at $298 \mathrm{~cm}^{-1}$ and $335 \mathrm{~cm}^{-1}$, but an asymmetric weaker band at $360 \mathrm{~cm}^{-1}$ in the case of annealed substrate (Fig. 5). This change is attributed to much bigger gold islands on the top of Si nanowires (Fig. 1).

Para-mercaptobenzoic acid is a suitable SERS test molecule able to bind both on gold and silver nanoparticles [43-47]. It was one of several benzoic acid derivatives for which Guo et al. performed time-dependent density functional theory calculation of possible HOMO and LUMO states [48]. It turns out that at different $\mathrm{pH}$, LUMO available orbital has different electron density, for low $\mathrm{pH}$ it is spread over all molecule, while for high $\mathrm{pH}$ it is almost exclusively localized on $-\mathrm{S}-\mathrm{H}$ group. Michota and Bukowska used roughened silver or gold electrodes at various voltages for obtaining SERS spectra of 4MBA [44]. When gold surfaces were prepared, 4MBA attached itself with sulphur atom to the gold one, irrespectively of $\mathrm{pH}$. They observed two bands characteristic for $-\mathrm{COO}^{-}$group, the symmetric stretching band at $1370-1380 \mathrm{~cm}^{-1}$, and the bending of $\mathrm{COO}^{-}$group at $848 \mathrm{~cm}^{-1}$. These two bands occur when $\mathrm{pH}$ is approximately neutral, and we have recorded them in our SERS spectra of $10^{-5} \mathrm{M} 4 \mathrm{MBA}$ (spectrum C, Fig. 4., and Supplementary Fig. S2). The absence of $2580 \mathrm{~cm}^{-1}$ band assigned to $\nu(\mathrm{S}-\mathrm{H})$ is conclusive of binding via sulphur atom (Fig. 5).

Raman mapping of an annealed vs. not-annealed substrate was performed in order to explain the better quality of SERS spectra in notannealed samples (Fig.5). In Fig. 6a and Fig. 6b the density of hot spots is compared by analyzing the integrated Raman intensity of the $1520-1640 \mathrm{~cm}^{-1} 4 \mathrm{MBA}$ band.

Not-annealed substrates presented a more homogeneous distribution of hot spots with respect to annealed ones, according to intensity maps and area distribution histograms in Fig.6. In annealed substrates, high intensity values are only observed but in few isolated spots, on a background of low-intensity values. On the other hand, in nonannealed substrates, the dimensions of the high-intensity spots were larger, on an overall background of medium-intensity values. It seems that larger dimensions of the nanostructures obtained by annealing with respect to non-annealed substrates (as seen in Fig.1) are less efficient in enhancing the signal. Their structural inhomogeneity exists on a larger scale, leading to a worse intra-substrate repeatability.

In order to experimentally determine the ratio of Raman intensity for gold-coated not annealed silicon nanowires and pure silicon nanowires, we performed Raman mapping of the two substrates previously immersed into $10^{-4} \mathrm{M}$ solution of 4MBA for $30 \mathrm{~min}$ and dried. The intensity ratio of the background corrected average SERS spectra is 234 


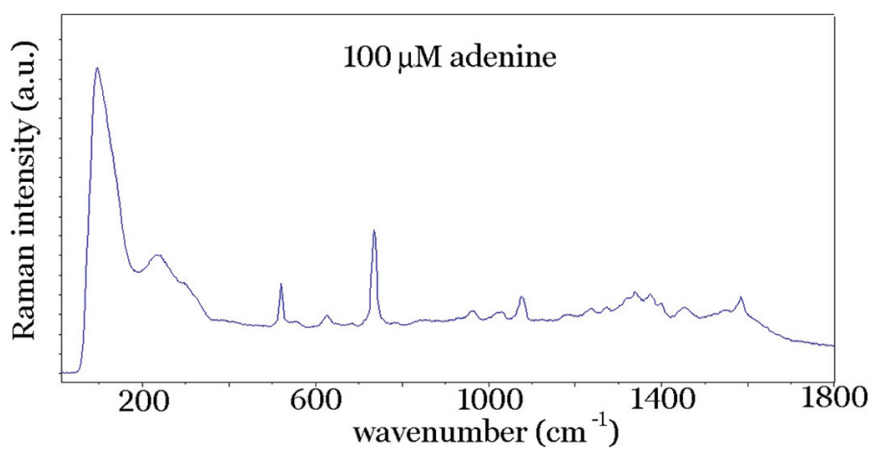

Fig. 8. SERS spectrum of $100 \mu \mathrm{M}$ solution of adenine on AuNP@SiNW substrate cleaned with $30 \mathrm{mM} \mathrm{AgNO}_{3}$, sputtered with gold for $7 \mathrm{~min}$, not annealed. Recorded with BwTek spectrometer, $785 \mathrm{~nm}$ excitation. Low frequency band at $100 \mathrm{~cm}^{-1}$ is an artefact due to notch filter. (For interpretation of the references to colour in this figure legend, the reader is referred to the web version of this article.)

(Fig. 7a and b). This is thus our estimate of the enhancement factor, assuming the same number of molecules is covering the area of mapped surfaces.

In Fig.8, a SERS spectrum of $100 \mu \mathrm{M}$ concentrated solution of adenine obtained on not annealed substrate is shown. We used it to test the usability of these substrates with another non-resonant analyte, and in particular for an analyte lacking a thiol - SH group. Adenine is a DNA base, a planar molecule with several - $\mathrm{NH}$ groups able to participate in hydrogen bonding. Since adenine disposes with two tautomers in neutral form, it is of interest to note that the strongest band we observed lies at $736 \mathrm{~cm}^{-1}$, corresponding to $\mathrm{N} 7$ tautomer in the notation of Pagliai et al. [49].

\section{Conclusion}

The gold-sputtered not annealed silicon nanowire hybrid substrates for surface-enhanced Raman scattering presented in this work have been proved highly efficient sensors for organic molecules disposing with thiol group. Para-mercaptobenzoic acid (4MBA) SERS spectra were compared with Raman and infrared spectra of polycrystalline powder and assigned with the help of normal coordinate calculation which followed an ab initio optimization of electronic and nuclear configuration. At neutral pH, 4MBA binds to gold on not annealed substrates, the bands at 298 and $335 \mathrm{~cm}^{-1}$ gaining the intensity. These two bands are assigned to in-plane $\mathrm{C}-\mathrm{C}-\mathrm{S}$ bending and $\mathrm{C}-\mathrm{S}$ stretching band. The stretching of $\mathrm{S}-\mathrm{H}$ (expected at cca $2550 \mathrm{~cm}^{-1}$ ) is never observed in any SERS spectrum.

The bending of $\mathrm{C}-\mathrm{O}-\mathrm{H}$ is predicted to contribute to two normal modes, 1223 and $1194 \mathrm{~cm}^{-1}$. The corresponding observed broad SERS band is centered around $1281 \mathrm{~cm}^{-1}$.

Surface distribution of substrate hot spots was obtained via Raman mapping of the $1520-1640 \mathrm{~cm}^{-1}$ interval both for annealed and not annealed substrates. Not annealed substrates proved to have more homogeneous distribution of hot spots and served as better enhancers of Raman signal.

Supplementary data to this article can be found online at https://doi. org/10.1016/j.saa.2018.04.016.

\section{Acknowledgement}

This work was supported by COST action BM1401, Raman-based applications for clinical diagnostics (Raman4Clinics)" through two shortterm missions. This work has been partly supported by Croatian Science Foundation under the Project No. IP-2014-09-7046 and by SAFU project KK.01.1.1.01.0001. Computations were performed at the University of Zagreb Computing Centre SRCE.

\section{References}

[1] M. Fleischmann, P.J. Hendra, A.J. McQuillan, Chem. Phys. Lett. 26 (1974) 163.

[2] D.L. Jeanmaire, R.P. van Duyne, J. Electroanal. Chem. 84 (1977) 1

[3] M.G. Albrecht, J.A. Creighton, J. Am. Chem. Soc. 99 (1977) 5215.

[4] M. Moskovits, Rev. Mod. Phys. 57 (1985) 783.

[5] M. Moskovits, Phys. Chem. Chem. Phys. 15 (2013) 5301-5311.

[6] F.S. Ameer, C.U. Pittman, D. Zhang, J. Phys. Chem C 117 (2013) 27096.

[7] Y.S. Yamamoto, T. Itoh, J. Raman Spectrosc. 47 (2016) 78-88.

[8] Surface-Enhanced Raman Scattering, H. Kneipp, M. Moskovits, in: K. Kneipp (Ed.), Topics in Applied Physics, 103, Springer Verlag, 2006.

[9] B. Sharma, M. Fernanda Cardinal, S.L. Kleinman, N.G. Greeneltech, R.R. Frontiera, M.G. Blaber, G.C. Schatz, R.P. Van Duyne, MRS Bull. 38 (2013) 615-624.

[10] P. Hildebrandt, M. Stockburger, J. Phys. Chem. 88 (1984) 5935-5944.

[11] A.M. Schwartzberg, C.D. Grant, A. Wolcott, C.E. Talley, T.R. Huser, R. Bogomolni, J.Z. Zhang, J. Phys. Chem. B 108 (2004) 19191-19197.

[12] K. Kneipp, H. Kneipp, J. Kneipp, Acc. Chem. Res. 39 (2006) 443-450.

[13] S.L. Kleinmann, E. Ringe, N. Valley, K.L. Wustholz, E. Phillips, K.A. Scheidt, G.C. Schatz, R.P. Van Duyne, J. Am. Chem. Soc. 133 (2011) 4115-4122.

[14] A. Dhawan, M. Gerhold, Y. Du, V. Misra, T. Vo-Dinh, Proc of SPIE 7205 (2009) 72050S-1.

[15] A.X. Wang, X. Kong, Dent. Mater. 8 (2015) 3024-3052.

[16] M. Jahn, S. Patze, I.J. Hidi, R. Knipper, A.I. Radu, A. Műhlig, S. Yüksel, V. Peksa, K. Weber, T. Mayerhőfer, D. Cialla-May, J. Popp, Analyst 141 (2016) 756-793.

[17] D.-K. Lim, K.-S. Jeon, H.M. Kim, J.-M. Nam, Y.D. Suh, Nat. Mater. 9 (2010) 60-67.

[18] J.M. McMahon, S. Li, L.K. Ausman, G.C. Schatz, J. Phys. Chem. C 116 (2012) 1627-1637.

[19] L. Angeloni, G. Smulevich, M.P. Marzocchi, J. Raman Spectrosc. 8 (1979) 305.

[20] COST, Action BM1401: Raman-based applications for clinical diagnostics (Raman4clinics), https://www.raman4clinics.eu/.

[21] A. Bonifacio, S. Cervo, V. Sergo, Anal. Bioanal. Chem. 407 (2015) 8265.

[22] L. Wu, Z. Wang, K. Fan, S. Zong, Y. Cui, Small 11 (2015) 2798-2886.

[23] S. Chen, Y. Yuan, S. Han, R. Gu, Chem. Commun. 47 (2011) 4225

[24] K.-O. Peng, Y.-J. Yan, S.-P. Gao, J. Zhu, Adv. Mater. 14 (2002) 1164

[25] C. Benoit, S. Bastide, C. Lévy-Clément, ECS Trans. 16 (2008) 245.

[26] N. Megouda, T. Hadjersi, S. Szunerits, R. Boukherroub, Appl. Surf. Sci. 284 (2013) 894.

[27] V. Sivakov, F. Voigt, B. Hoffmann, V. Gerliz, S. Christiansen, Intech "Nanowires Fundamental Research"ISBN 978-953-307-327-9, Chapter 32011.

[28] M. Becker, V. Sivakov, G. Andrä, R. Geiger, J. Schreiber, S. Hoffmann, J. Michler, A.P. Milenin, P. Werner, S.H. Christiansen, Nano Lett. 7 (2007) 75-80.

[29] M. Becker, V. Sivakov, U. Gősele, T. Stelzner, G. Andrä, H.J. Reich, S. Hoffmann, J. Michler, S.H. Christiansen, Small 4 (2008) 398-404.

[30] P.R. Brejna, P.R. Griffiths, Appl. Spectrosc. 64 (2010) 493-499.

[31] N. Bontempi, M. Salmistraro, M. Ferroni, L.E. Depero, I. Alessandri, Nanotechnology 25 (2014), 465705.

[32] X. Yang, H. Zhong, Y. Zhu, J. Shen, C. Li, Dalton Trans. 42 (2013) 14324-14330.

[33] W. Ming-Li, Z. Chang-Xing, W. Zheng-Long, J. Xi-Li, X. Hai-Jun, Chin. Phys. B. 23 (2014), 067802.

[34] H. Wang, X. Jiang, S.-T. Lee, Y. He, Small 10 (2014) 4455-4468.

[35] A. Convertino, V. Mussi, L. Maiolo, Nature Scientific Reports 6 (2016) 25099.

[36] S.A. Kara, A. Keffous, A.M. Giovanozzi, A.M. Rossi, E. Cara, L. D'Ortenzi, K. Sparnacci, L. Boarino, N. Gabouze, S. Soukane, RSC Adv. 6 (2016) 93649.

[37] H. Cui, S. Li, S. Deng, H. Chen, C. Wang, ACS Sensors 2 (2017) 386-393.

[38] H. Gebavi, L. Mikac, M. Marciuš, M. Šikić, V. Mohaček-Grošev, T. Janči, S. Vidaček, E. Hasanspahić, E. Omanović Miklićanin, M. Ivanda, Silicon nanowires substrates fabrication for ultra-sensitive surface enhanced Raman spectroscopy sensors, Croat. Chem. Acta 90 (2017) 256-262.

[39] C. Beleites, V. Sergo, Hyperspec: A package to handle hyperspectral data in R, R Package version 0.98-201-50304, 2015 http://hyperspec.r-forge.r-project.org.

[40] R Core Team, R: A Language and Environment for Statistical Computing, R Foundation for Statistical Computing, Vienna, Austria, 2016 https://www.R-project.org/.

[41] M.J. Frisch, G.W. Trucks, H.B. Schlegel, G.E. Scuseria, M.A. Robb, J.R. Cheeseman, J.A. Montgomery Jr., T. Vreven, K.N. Kudin, J.C. Burant, J.M. Millam, S.S. Iyengar, J. Tomasi, V. Barone, B. Mennucci, M. Cossi, G. Scalmani, N. Rega, G.A. Petersson, H. Nakatsuji, M. Hada, M. Ehara, K. Toyota, R. Fukuda, J. Hasegawa, M. Ishida, T. Nakajima, Y. Honda, O. Kitao, H. Nakai, M. Klene, X. Li, J.E. Knox, H.P. Hratchian, J.B. Cross, V. Bakken, C. Adamo, J. Jaramillo, R. Gomperts, R.E. Stratmann, O. Yazyev, A.J. Austin, R. Cammi, C. Pomelli, J.W. Ochterski, P.Y. Ayala, K. Morokuma, G.A. Voth, P. Salvador, J.J. Dannenberg, V.G. Zakrzewski, S. Dapprich, A.D. Daniels, M.C. Strain, O. Farkas, D.K. Malick, A.D. Rabuck, K. Raghavachari, J.B. Foresman, J.V. Ortiz, Q. Cui, A.G. Baboul, S. Clifford, J. Cioslowski, B.B. Stefanov, G. Liu, A. Liashenko, P. Piskorz, I. Komaromi, R.L. Martin, D.J. Fox, T. Keith, M.A. Al-Laham, C.Y. Peng, A. Nanayakkara, M. Challacombe, P.M.W. Gill, B. Johnson, W. Chen, M.W. Wong, C. Gonzalez, J.A. Pople, Gaussian03, Revision C.02, Gaussian, Inc., Wallingford, CT, 2004.

[42] MOLVIB, Program developed by K. Kuczera and J. Wiorkiewicz-Kuczera at Harvard University, 1990

[43] H. Gebavi, D. Ristić, N. Baran, L. Mikac, V. Mohaček-Grošev, M. Gotić, M. Šikić, M. Ivanda, Mater. Res. Express 5 (2018), 015015.

[44] A. Michota, J. Bukowska, J. Raman Spectrosc. 34 (2003) 21.

[45] W.-Q. Ma, Y. Fang, G.-L. Hao, W.-G. Wang Chin, J. Chem. Phys. 23 (2010) 659.

[46] A. Dhawan, IEEE Sensors J. 10 (2010) 608-616.

[47] F. Wang, R.G. Widejko, Z. Yang, K. Van, T. Ngyen, H. Chen, L.P. Fernando, K.A. Christensen, J.N. Anker, Anal. Chem. 84 (2012) 8013.

[48] H.-B. Guo, F. He, B. Gu, L. Liang, J.C. Smith, J. Phys. Chem. A 116 (2012) 11870

[49] M. Pagliai, S. Caporali, M. Muniz-Miranda, G. Pratesi, V. Schettino, J. Phys. Chem. Lett. 3 (2012) 242. 